\title{
Regional distribution of gas in the lung
}

\author{
Joseph Milic-Emili CM MD FRSC \\ Meakins-Christie Laboratories, McGill University, Montreal, Quebec
}

\begin{abstract}
J Milic-Emili. Regional distribution of gas in the lung. Can Respir J 2000;7(1):71-76.

In 1966, a paper entitled "Regional distribution of gas in the lung" was published in the Journal of Applied Physiology and became one of the 100 most-cited papers of clinical research from 1961 to 1978 . The senior author provides the background and state-of-the art at the time of its publication, and reviews the main findings of the paper and subsequent developments.
\end{abstract}

Key Words: Closing volume; Elastic properties; Lung; Regional pleural pressure

\begin{abstract}
Distribution pulmonaire régionale des gaz
RÉSUMÉ : En 1966, un article intitulé «Regional distribution of gas in the lung» a été publié dans le Journal of Applied Physiology et est devenu l'un des 100 articles les plus souvent cités en recherche clinique entre 1961 et 1978. Son auteur vénérable nous présente ici l'historique et l'état des connaissances scientifiques à l'époque de sa publication et il passe en revue les principales conclusions de l'article et les développement qui en ont découlé.
\end{abstract}

Wonder, rather than doubt, is the root of knowledge.

\section{Abraham Heschel}

$\mathrm{T}$ The 1966 paper entitled "Regional distribution of gas in the lung" (1) became one of the 100 most-cited papers of clinical research from 1961 to 1978 (2). It inspired many investigations and provided the kernel for understanding regional lung function $(3,4)$. It also played an important role in propelling me to become one of the 1,000 most-cited authors from 1965 to 1978 (5). Before this study, my research training in Milan, Liège and Boston was essentially 'programmed' to allow me to formulate concisely the basic factors determining the regional distribution of gas in the lung.

Milan and Liège: From 1956 to 1959, I worked at the Department of Physiology at the University of Milan, Italy with
Professor Rodolfo Margaria, both of which, at the time, were devoted to research in exercise physiology. My introduction to respiratory mechanics began in 1957 when a very capable Belgian physiologist, Jean-Marie Petit, came, through a misunderstanding, to our department to learn how to measure esophageal pressure. Such measurements had not been done in Milan, nor was there any suitable equipment available. Nevertheless, using a water manometer, we produced an important paper on the measurement of esophageal pressure (6). Dr Petit, who was one of the best experimental physiologists that I have ever known, invited me to join him in his laboratories in Liège, Belgium, which were well equipped for studies in respiratory mechanics, and together we produced a large series of papers in this field. Thus, I became an expert in respiratory mechanics through a fortuitous misunderstanding. Boston: From 1960 to 1963 , I was a research fellow at the 


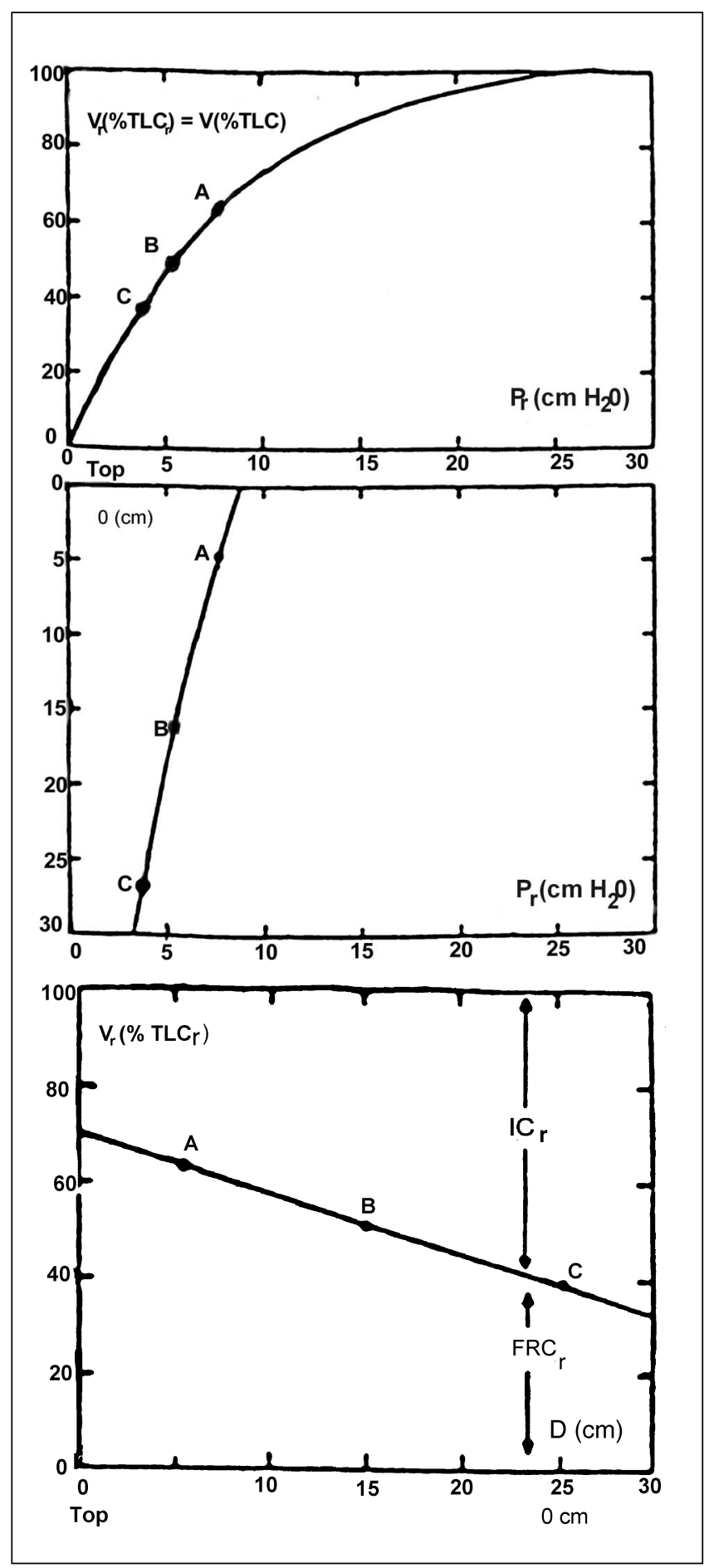

Figure 1) Top Regional static volume-pressure relationship of the lung, which is assumed to be isotropic. Regional and overall lung volume are expressed respectively as a percentage of regional total lung capacity (TLCr) and overall total lung capacity (TLC). Middle Regional transpulmonary pressure at different vertical distance $(D)$ down the lung at functional residual capacity (FRC). Bottom Regional lung volume ( $\mathrm{Vr})(\% \mathrm{TLCr})$ as a function of $D$. The letters A, $B$ and $C$ indicate how the regional FRCr in the bottom panel was computed from the corresponding relations in the other panels. For further information, see text. Adapted from reference $1 . \mathrm{ICr}$ Regional inspiratory capacity; V Volume; Pr Transpulmonary pressure
Harvard School of Public Health, Boston, where, under the guidance of Dr Jere Mead, I published two papers dealing with the static volume-pressure (V-P) relationship of the lung and the topography of pleural surface pressure $(7,8)$. With the above research background, the solution to the factors governing regional lung function was inevitable, perhaps even pedestrian, as shown below.

\section{BACKGROUND}

Before 1966, studies with inert gases, differential lobar bronchospirometry and, more recently, with radioactive gas methods using external counters showed that ventilation in the normal human lung was uneven and that this unevenness had a topographical distribution $(3,4)$. However, the mechanisms determining this unevenness were poorly understood. Retrospectively, this is surprising because the essential elements governing the regional distribution of gas in the lung were known. Indeed, it had been known since 1961 that there is a vertical gradient in pleural pressure of about $0.2 \mathrm{~cm} \mathrm{H}_{2} \mathrm{O} / \mathrm{cm}$ descent in the lung (9), and my own work at the Harvard School of Public Health supported these results (8). At the same institution, based on experiments on excised pulmonary lobes of dogs, Frank (10) concluded that, at least at a lobar level, the static mechanical properties of the lung are relatively uniform. That is, the static V-P relationships of the various lobes are essentially the same, provided that volumes are expressed as a percentage of the total lobar volume measured at the same distending pressure. Although the evidence was less certain, the consensus at the Harvard School of Public Health at that time was that the intrinsic elastic properties were probably isotropic, also at a gross sublobar level. This implied that regional static V-P relations, normalized for regional total lung capacity (TLCr), were similar to the overall static V-P curve of the lung, normalized for overall total lung capacity (TLC). Accordingly, the overall static V-P curve of the lung (V, \% TLC) obtained with the esophageal balloon method (7) also pertains to different lung regions (regional lung volume [Vr], \% TLCr), as shown in the top panel of Figure 1. The middle panel of Figure 1 depicts the regional distribution of static transpulmonary pressure $(\mathrm{Pr})$ at functional residual capacity (FRC): Pr decreases by about $0.2 \mathrm{~cm} \mathrm{H}_{2} \mathrm{O} / \mathrm{cm}$ descent down the lung $(8,9)$. Based on this information, it is possible to compute the regional lung expansion $(\mathrm{Vr}, \% \mathrm{TLCr})$ as a function of vertical distance (D) down the lung (bottom panel of Figure 1). Indeed, at a distance of $5 \mathrm{~cm}$ from lung top, $\mathrm{Pr}$ at $\mathrm{FRC}$ is $7.6 \mathrm{~cm} \mathrm{H}_{2} \mathrm{O}$, as indicated by point $\mathrm{A}$ in the middle panel of Figure 1. This corresponds to a $\mathrm{Vr}$ of $63 \%$ $\mathrm{TLCr}$, as indicated by point A in the top panel. This volume is next plotted against a $D$ of $5 \mathrm{~cm}$ in the middle panel. Using a similar approach (eg, points B and C), it is possible to compute the regional volume expansion over the entire distance down the lung (solid line). Because the relationships in Figure 1 pertain to FRC, the middle panel represents the regional distribution of FRC (FRCr) down the lung, while the vertical distance from the FRCr line to the upper abscissa 
(which equals 100\% TLCr) reflects the regional inspiratory capacity (ICr).

Although the regional distribution of gas at different vertical levels of the lung could have been predicted before our 1966 study (1), it had not been done. In this regard, I will note that the nature and magnitude of the vertical pleural pressure gradient down the lung, as well as the problem of homogeneity and nonhomogeneity of regional lung mechanics, were topics that were hotly discussed at many seminars held at the Harvard School of Public Health. Nevertheless, the basically straightforward step of predicting the regional distribution of gas based on the available information had not been attempted. This reinforces my opinion that seminars are an excellent vehicle to improve scientific reasoning and background knowledge, but seldom provide important scientific breakthroughs.

Montreal: In 1963, I was invited by David V Bates to come to McGill University, Montreal, Quebec. His group had introduced a quantitative method for assessing regional pulmonary function using ${ }^{133}$ Xenon (11). Their paper, which was also among the 100 most-cited articles of clinical research (1961 to 1978), provided a quantitative method to study regional lung function.

My arrival to Canada was somewhat hectic because I was asked by Canadian immigration to provide a chest X-ray. This showed that I had overt tuberculosis! Nevertheless, I was allowed to come to Canada on a special minister's permit, thanks to strenuous efforts by Drs David Bates and Maurice McGregor. I am very grateful because I have spent a very happy time at McGill University. Unknown to me at that time, in view of my background training, I was ready to make a rapid breakthrough at McGill in the area of regional lung function.

I arrived to Montreal in the middle of the summer of 1963, at a time when all the staff were on vacation. I was put in a small office with a single reprint on my desk, that of Ball et al (11). I proceeded to read it with interest, particularly as I thought that the studies with radioactive gases were a new, rather exotic area of research. On the fourth page of that paper were two equations that described the $\mathrm{Xe}^{133}$ method, and which, at first, I could not understand. After a while, however, I realized that the method of Ball et al (11) was merely an application of the gas dilution principle, with which one could measure, for example, the FRCr at different levels down the lung, ie, the missing link in Figure 1 (middle panel). In fact, at that moment I realized the significance of my previous research (6-8) in terms of regional lung expansion. For the first time in my life, I was now in full control of a research line that rapidly led to the experimental verification of the analysis in Figure 1 and the development of the 'onion skin diagram' (Figure 2).

Peer review: The manuscript entitled "Regional distribution of inspired gas in the lung" (1) was submitted for publication to the Journal of Applied Physiology at the beginning of 1965, together with three companion papers (12-14). The name of Dr Bates does not appear in the primary paper because he told

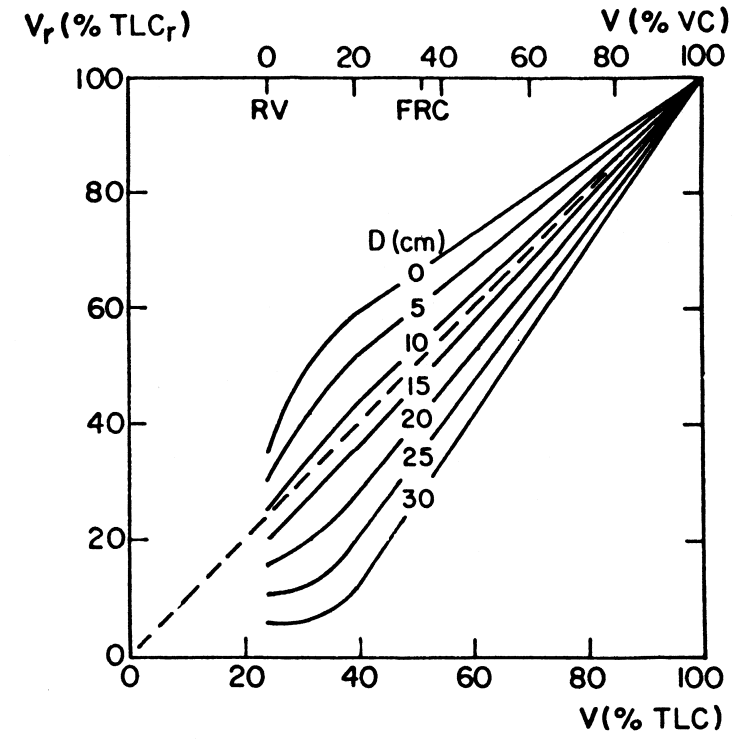

Figure 2) Regional lung volume ( Vr), expressed as a percentage of regional total lung capacity (TLCr). Abscissa: overall lung volume $(V)$, expressed as percentage of total lung capacity $(T L C)$ below and as a percentage of vital capacity $(V C)$ above. The broken line (line of identity) indicates the percentile degree of expansion of the regions equal to that for the entire lungs. The vertical distance ( $D$ ) from top of lungs (in $\mathrm{cm}$ ) is indicated on each curve. From reference 1. RV Residual volume; FRC Functional residual capacity. Reproduced with permission from reference 1

me that, in view of the importance of the study, he wanted to leave all the credit to me! Such generosity is seldom encountered. His name, however, appears on "Regional distribution of ventilation and perfusion as a function of body position "(13).

While the three companion papers received favourable reviews, this was not the case with reference 1 , which was rejected! One of the two reviewers concluded the extensive criticism with the following statement: "My comments should be considered merely citations of examples of the faults in this paper rather than an exhaustive catalog." Among his long list of faults he stated that "one of the serious problems of your presentation was that you have used \% TLC and \% TLCr as units of volume." In fact, these units were pivotal for understanding the regional distribution of gas in the lung. Clearly, this reviewer had more doubt than wonder.

Despite the adamant rejection of our paper, the section editor, Dr Jere Mead, decided to accept it for publication. In reference to this, I will add that one of the reviewers of the companion paper entitled "Regional distribution of pulmonary perfusion in erect man" (12) wrote that "While reading the manuscript I felt like listening to the music of Wagner." In his correspondence with us, Dr Mead stated that he accepted this paper on the assumption that the reviewer actually liked Wagner's music!

\section{WHAT WAS DISCOVERED}

The 1966 paper provides a quantitative validation of the factors governing the regional distribution of gas within 


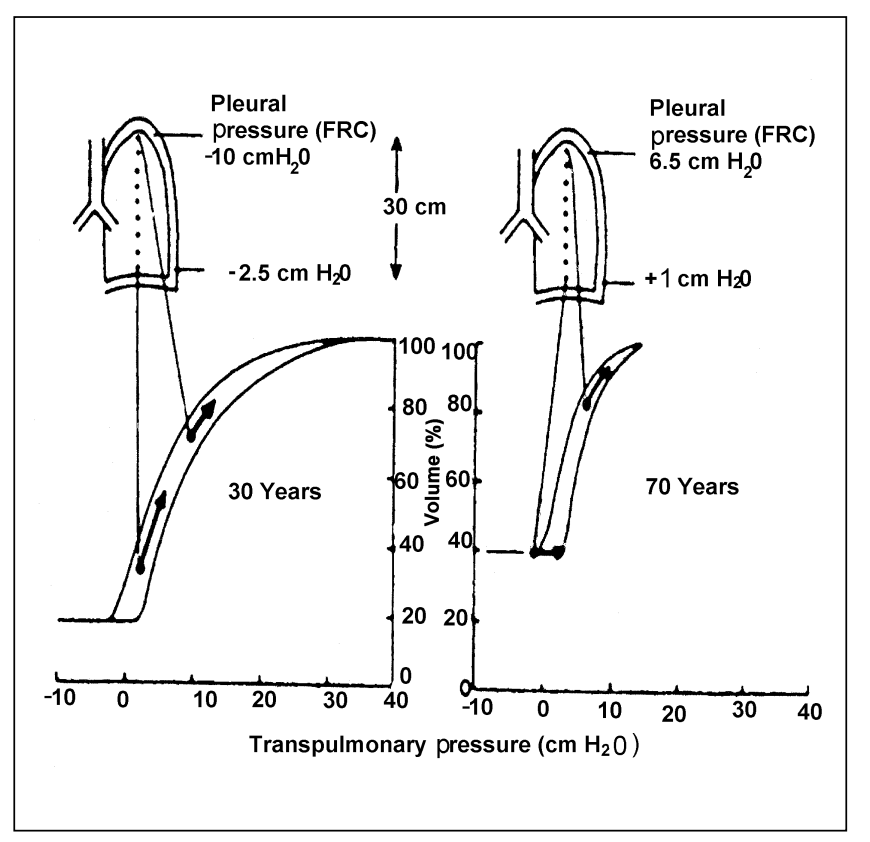

Figure 3) Distribution of ventilation during quiet breathing in a young (left) and in an old subject (right). In the old subject, at functional residual capacity $(F R C)$ the pleural pressure is positive at the lung base, causing airway collapse, so that ventilation is distributed preferentially to the upper zones (see arrows). Note the loss in elastic recoil of the lungs in the old subject, ie, the static volumepressure curve is displaced to the left. Reproduced with permission from reference 15

the lung, outlined in Figure 1. Furthermore, it introduced the 'onion skin diagram' depicted in Figure 2. This diagram was derived from data collected from a seated, normal young man after he had inhaled air labelled with $\mathrm{Xe}^{133}$. Regional count rates over different parts of the chest were measured using 12 scintillation counters. This is another way of plotting the information in the right upper panel of Figure 1, except that regional volume is plotted against overall lung volume, and the vertical distance down the lung is depicted by the different isopleths. Figure 3 depicts the distribution of ventilation during quiet breathing in a normal young man (1), together with that observed on an elderly normal man (15).

Progress in physiology is often marked by the development of diagrams that provide a concise formulation of basic aspects. In respiratory physiology, there are many examples, such as the oxygen-carbon dioxide diagram of Rahn and Fenn (16). Our study also provided such a diagram, namely the 'onion skin diagram' (Figure 2). For upright humans, Figure 2 indicates a number of things. The alveoli in the upper lung regions are more expanded than in the lower lung zones at all lung volumes, except at full inflation (100\% TLC). Above FRC there is nonsequential lung filling. This is reflected by the linear relationships between regional and overall lung volume, with the ventilation per alveolus being higher in the lower lung zones, reflected by the steeper slopes of the lines. Below FRC, lung emptying is sequential, reflecting progressive small airway closure in the dependent lung zones as residual volume is approached. Lung regions empty progressively with decreasing lung volume until a minimal limiting volume is reached. This limiting volume reflects gas trapping behind closed small airways. These findings led to the concept and measurement of the closing volume (17). Incidentally, that paper was also originally rejected.

After publication, our paper became very popular immediately, stimulating a vast number of physiological and clinical investigations, which have been extensively reviewed elsewhere $(3,4,18,19)$. Furthermore, our main findings are now described in most textbooks of respiratory physiology, and have become part of the physiological heritage. It is axiomatic, however, that scientific diagrams, such as Figures 1 and 2, have limitations in view of the complexity of the respiratory system and the 'scientific' approach on which they are based.

Broadly speaking, the approach to a given topic can be 'mystic' or 'scientific': perception of the whole versus selection of parts. Because 'scientific' accounts are by definition selective, they provide only a partial story. As a result, all 'scientific' diagrams have limitations because they are necessarily based on simplifying assumptions. The limitations of Figures 1 and 2 will become apparent below.

\section{KNOWLEDGE GAINED SINCE 1966}

Since 1996, there has been considerable progress in the understanding of regional lung function, as described elsewhere $(3,4,18,19)$. This account will be limited mainly to a review of the limitations of Figures 1 and 2, which pertain to static or quasistatic conditions.

The regional distribution of gas depends on many factors, which include: shape of the static V-P curve of the lung; regional differences in elastic properties of the lung; regional changes in $\Delta \mathrm{Pr}$, which can vary depending on the strength of respiratory muscle contraction as well as type of contracting muscle (eg, diaphragm versus external intercostal accessory muscles); regional differences in flow resistance; and flow rates.

In experimental animals and humans, the static V-P curve of the lung appears to be exponential in character, a fact that is consistent with nonsequential lung filling and emptying at lung volumes greater than FRC (Figure 2) (1). However, in most experimental animals, there are small but consistent differences in elastic properties between the upper and lower lung lobes $(18,19)$. Although a study on normal excised human lung lobes suggested that such differences are not present in humans (20), studies with the single-breath washout method at 1G (normal gravity) and during sustained microgravity (Spacelab SLS-1) suggest that, in humans, there are also regional differences in elastic properties, which result in some degree of sequential lung emptying at volumes greater than FRC (21).

The question of whether the changes in $\Delta \operatorname{Pr}$ are regionally uniform is of considerable theoretical and practical interest. Indeed, apart from the implications on regional distribution 
of ventilation, the presence of regional differences in $\Delta \mathrm{Pr}$ could profoundly affect all measurements of lung mechanics based on the determination of $\Delta \mathrm{Pr}$ in a circumscribed area of the lung. In fact, most lung mechanics measurements are performed with the esophageal balloon technique that involves determination of local pressure (8). If $\Delta \mathrm{Pr}$ is not uniform, measurements of pulmonary flow resistance and dynamic lung compliance are questionable because the local changes in Pr, which are measured via the esophageal balloon, may not reflect the 'overall' (average) change in pressure over the whole lung surface (18). However, there is evidence that suggests that in normal humans, under most physiological conditions, the changes in Pr are relatively uniform (22). In this study, the changes in mouth pressure during a spontaneous inspiration against a closed tap were compared with those in esophageal pressure. While in sitting and lateral postures, the changes in esophageal and mouth pressure were relatively close. While in the supine position in the same instance, the $\Delta \mathrm{P}$ at the mouth differed substantially from that in the esophagus. Because in the above experiments the changes in occluded mouth pressure reflected the 'overall' changes in pressure over the whole lung surface, the concordance between local (esophageal) $\Delta \mathrm{P}$ and overall (mouth) $\Delta \mathrm{P}$ suggests that in spontaneously breathing subjects the changes of pleural pressure are relatively uniform, at least in sitting and lateral decubitus positions. It should be noted, however, that even small regional differences in $\Delta \operatorname{Pr}$ may influence the regional distribution of ventilation and contribute to sequential lung emptying at lung volumes greater than FRC (4). More marked nonuniform changes in $\Delta \mathrm{Pr}$, sufficient to cause substantial changes in regional distribution of gas, can be achieved by selective voluntary contraction of different respiratory muscles, as first demonstrated by Roussos et al (23).

There is virtually no information concerning regional flow resistance. Regional differences in bronchomotor tone, viscoelastic behaviour and other factors inherent in the complex geometry and aerodynamics of the airways may well cause substantial regional differences in flow resistance. Clearly, further studies are needed to resolve this topic, which must play an important role in distribution of ventilation, particularly during muscular exercise.

Since the early work of Robertson et al (24), it has been amply shown that the regional distribution of gas changes with increasing flow rates $(4,19)$. This point was further explored by Pedley et al (25), whose model predictions were in general qualitative agreement with the experimental results. However, there are not yet any systematic studies of the regional distribution of ventilation during exercise.

Clearly, further work is needed before the factors determining the static dynamic distributions of gas within different regions of the lungs are fully understood. Nevertheless, the present knowledge has provided useful information to explain the abnormalities in regional distribution of ventilation and gas exchange in a variety of pulmonary and cardiac disorders.

Finally, it should be noted that during normal tidal breath- ing in the upright posture, the primary determinants of ventilatory inhomogeneity are not gravitational in origin. Indeed, under these conditions, the overall distribution of ventilation is only slightly less inhomogeneous in microgravity than at $1 \mathrm{G}(26)$. By contrast, transition from standing to supine position at $1 \mathrm{G}$ results in significantly increased inhomogeneity of ventilation distribution.

Postscript: The 1966 article, although written in a clear and concise fashion, is not easy to read, because it requires considerable knowledge of both respiratory mechanics and gas exchange. It still is, however, the essential synthesis of the factors that govern regional distribution of gas in the lung. In preparing this manuscript, however, I found that, at this time in my life, the names of my co-workers have become more important to me than the scientific content of the paper. We had a good time! In particular, I wish to acknowledge the major scientific contributions made by Dr Kenzo Kaneko and Myrna B Dolovich, and their friendship.

ACKNOWLEDGEMENT: I wish to thank Angie Bentivegna for typing this manuscript.

\section{REFERENCES}

1. Milic-Emili J, Henderson JA, Dolovich MB, Trop D, Kaneko K. Regional distribution of inspired gas in the lung. J Appl Physiol 1966;21:749-59.

2. Garfield E. Most-cited articles in the 1960s. Clinical research. Current Contents 1980;6:5-14.

3. West JB. Regional differences in the lung. New York: Academic Press, 1977.

4. Milic-Emili J. Topographical inequality of ventilation. In: Crystal RG, West JB, Weibel ER, et al eds. The Lung. Philadelphia : Raven Publishers, 1997:1415-23.

5. Garfield E. The 1,000 most-cited contemporary authors. Current Contents 1982;22:5-13.

6. Petit JM, Milic-Emili G. Measurement of esophageal pressure. J Appl Physiol 1958;13:481-5.

7. Milic-Emili J, Mead J, Turner JM, Glauser EM. Improved technique for estimating pleural pressure from esophageal balloons. J Appl Physiol 1964;19:207-11.

8. Milic-Emili J, Mead J, Turner JM. Topography of esophageal pressure as a function of posture in man. J Appl Physiol 1964;19:212-6.

9. Kruger JJ, Bain T, Patterson JL Jr. Elevation gradient of intathoracic pressure. J Appl Physiol 1961;16:465-8.

10. Frank NR. A comparison of static volume-pressure relations of excised pulmonary lobes of dogs. J Appl Physiol 1963;18:274-8.

11. Ball WC Jr, Stewart PB, Newsham LGS, Bates DV. Regional pulmonary function studied with xenon ${ }^{133}$. J Clin Invest 1962;41:519-31.

12. Anthonisen NR, Milic-Emili J. Distribution of pulmonary perfusion in erect man. J Appl Physiol 1966;21:760-6.

13. Kaneko K, Milic-Emili J, Dolovich MB, Dawson A, Bates DV. Regional distribution of ventilation and perfusion as a function of body position. J Appl Physiol 1966;21:767-77.

14. Bryan AC, Milic-Emili J, Pengelly LD. Effect of gravity in the distribution of pulmonary ventilation. J Appl Physiol1966;21:778-84.

15. Milic-Emili J, Henderson JAM, Kaneko K. Regional distribution of pulmonary ventilation. In: Cumming G, Hunt LB, eds. Form and Function in the Human Lung. Edinburgh: ES Livingstone Ltd, 1968:66-75.

16. Rahn H, Fenn WO. A graphical analysis of respiratory gas exchange; the O2-CO2 diagram. Washington: American Physiological Society, 1955.

17. Dolfuss RE, Milic-Emili J, Bates DV. Regional ventilation of the lung studied with boluses of ${ }^{133}$ Xenon. Respir Physiol 1967:2:234-46. 
18. Milic-Emili J. Pulmonary statics. In: Widdicombe JG, ed. MTP International Review of Science: Respiratory Physiology. London: Butterworths, 1974:105-37.

19. Milic-Emili J. Ventilation. In: West JB, ed. Regional Differences in the Lung. New York: Academic Press, 1977:167-99.

20. Berend N, Skoog C, Thurlbeck WM. Lobar pressure-volume characteristics of excised human lungs. Thorax 1981;36:290-5.

21. Guy HJ, Prisk GK, Elliott AR, Deutschman RA 3rd, West JB. Imhomogeneity of pulmonary ventilation during sustained microgravity as determined by single-breath washouts. J Appl Physiol 1994;76:1719-29.

22. Baydour A, Behrakis PK, Zin WA, Jaeger M, Milic-Emili J.
A simple method for assessing the validity of the esophageal balloon technique. Am Rev Respir Dis 1982;126:788-91.

23. Roussos CS, Fixely M, Genest J, et al. Voluntary factors influencing the distribution of inspired gas. Am Rev Respir Dis 1977;116:457-67.

24. Robertson PC, Anthonisen NR, Ross D. Effect of inspiratory flow on regional distribution of inspired gas. J Appl Physiol 1969;26:438-43.

25. Pedley T, Sudlow JMG, Milic-Emili J. A nonlinear theory of the distribution of pulmonary ventilation. Respir Physiol 1972;15:1-38.

26. Prisk GK, Guy HJ, Elliott AR, Paiva M, West JB. Ventilatory inhomogeneity determined from multiple-breath washouts during sustained microgravity on Spacelab SLS-1. J Appl Physiol 1995;78:597-607. 


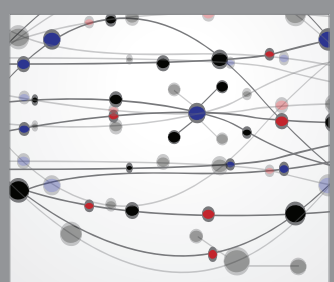

The Scientific World Journal
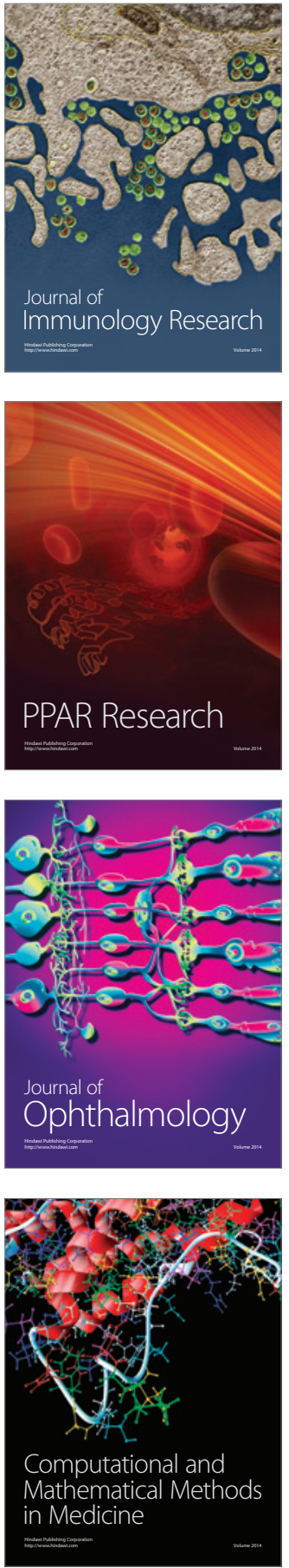

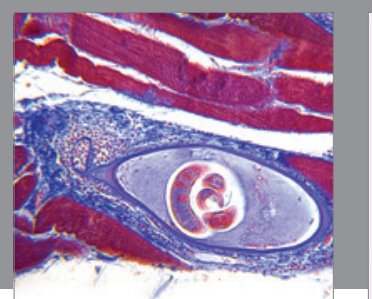

Gastroenterology Research and Practice

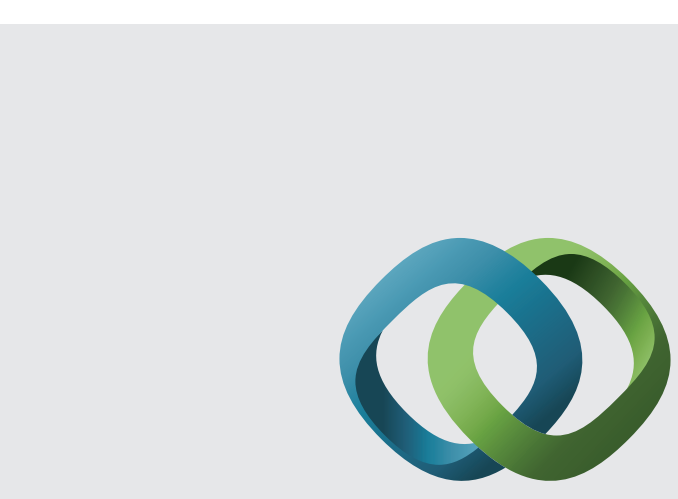

\section{Hindawi}

Submit your manuscripts at

http://www.hindawi.com
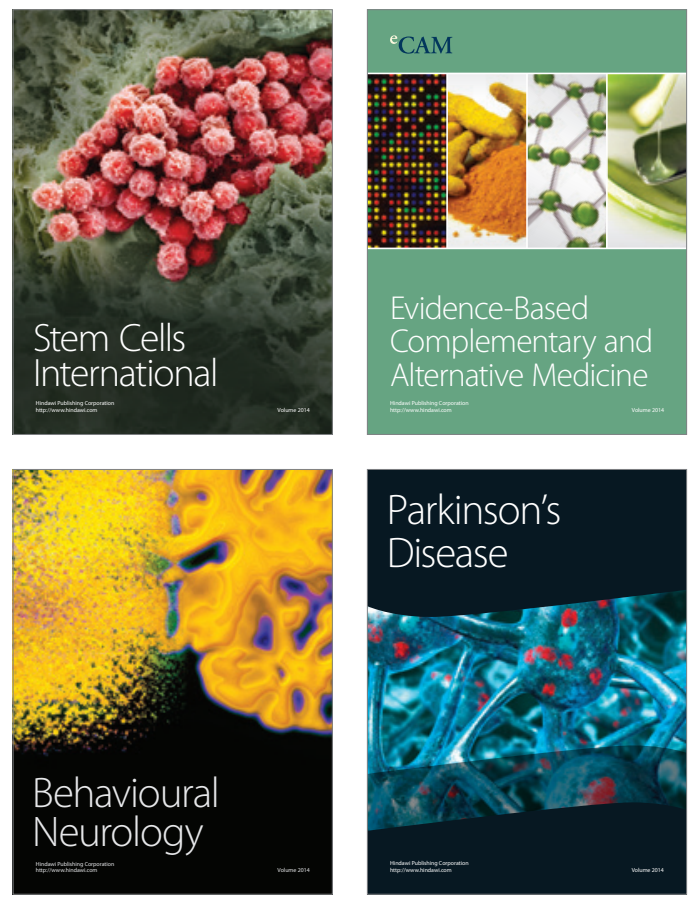
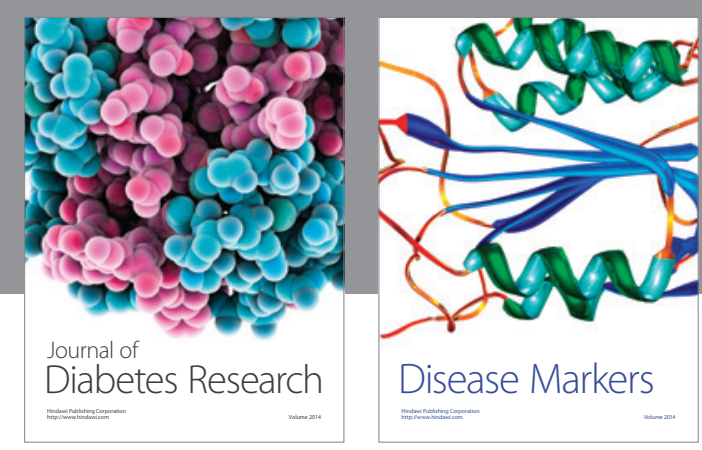

Disease Markers
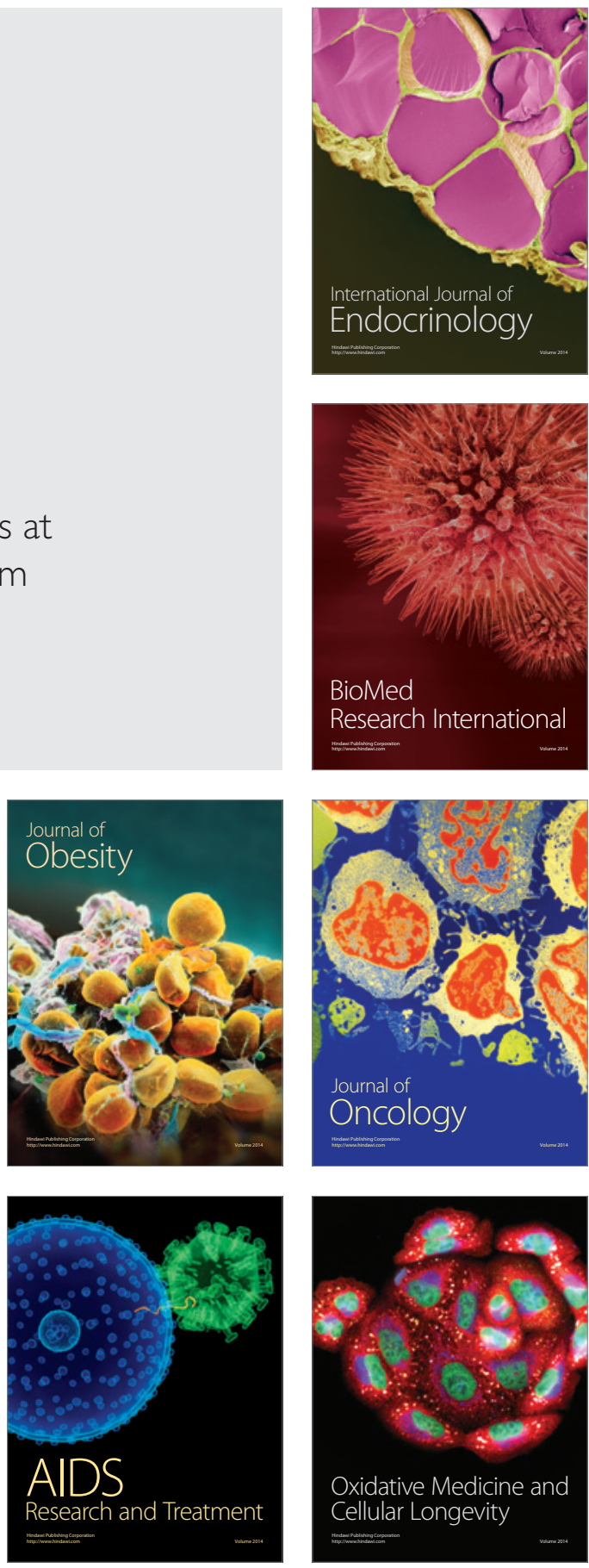